Research Article

\title{
Numerical Simulation Algorithm Design of Influence on Existing Tunnel by Underpass Construction of New Tunnel
}

\author{
Huajun Wu \\ Yiwu Industrial and Commercial College, Yiwu, Zhejiang 322000, China \\ Correspondence should be addressed to Huajun Wu; ywgswhj@ywicc.edu.cn
}

Received 9 October 2021; Revised 28 November 2021; Accepted 30 November 2021; Published 16 December 2021

Academic Editor: Rahman Ali

Copyright $\odot 2021$ Huajun Wu. This is an open access article distributed under the Creative Commons Attribution License, which permits unrestricted use, distribution, and reproduction in any medium, provided the original work is properly cited.

\begin{abstract}
Simulation is a powerful tool that can be used for systematic planning, analysis, and decision-making. Proper designing is preliminary required to construct a new tunnel over an existing tunnel to ensure safety and durability. Once an underpass tunnel completes, the interaction between the tunnel structure and the nearby soil gains a stable state and the stress of the tunnel is balanced. However, the stability of an existing tunnel is affected if the construction in the nearby area is not properly analyzed. This article proposes a numerical simulation model to empirically analyze lining force and surface settlement in order to ensure safety in engineering practice. The existing tunnel structure working condition is simulated under the new tunnel. The artificial honeybee colony algorithm is used to extract the parameter fusion characteristic value of tunnel influence and the model of estimating the bending moment of group piles. The structural mechanics of existing tunnels under new tunnels are analyzed using the triple bend model to improve the bearing capacity of existing tunnels under new tunnels. Based on the above analysis, numerical simulation experiments are designed. The proposed method has high accuracy and strong fitting ability and can effectively reduce the displacement of existing tunnels. Moreover, the method can improve the bearing capacity of tunnels. For tunneling operation, the results of the simulation may be used as a recommendation.
\end{abstract}

\section{Introduction}

With the rampant expansion of urbanization, the means of transportation is also increasing exponentially. Demands for the construction of new metro routes, tracks, and rail transit are also rising accordingly. With the development of urban rail transit, it is unavoidable to cross the old and new metro tracks [1]. Due to congestion in urban areas and the shortage of space, the construction of more than one tunnel at one site is becoming the ultimate option. In this day and age of prevailing urbanization, it is not uncommon that the formation of the metro network and underpass tracks passes through an existing underpass tunnel [2]. Construction of tunnels within the built environment requires comparatively more support and geotechnical strength [3]. Construction of new tunnels may not only weaken the existing tunnel, but the high-rise buildings nearby may also be subject to ground movements. How to control the deformation of both new and existing tunnels is an important problem in engineering construction [4]. For the safe operation of existing tunnels, it is of great significance to deal with the deformation law of the existing tunnel, its structure, and settlement protection measures. In order to reduce the influence of underpass construction on existing tunnels and ensure the safe operation of the subway, it is necessary to study the influence law and parameter control of underpass construction.

One of the most effective uses of computer technology that have revolutionized civil engineering is computer-based simulation [4]. Numerical simulation has been preferred for its low cost and feasible operability. The simulation can be used for the geometry and the geological and geotechnical details of various construction materials. Researchers believe that numerical analysis must be carried out when the ratio $\sigma_{\mathrm{cm}} / \rho_{0}$ falls from the threshold of 0.15 [5]. The use of numerical simulation is not only effective for the systematic construction of tunnels but also useful for environmental protection. In order to explore the impact of new tunnel underpass construction on the existing expressway and select a more suitable construction method for the new tunnel, taking a new shallow buried and concealed tunnel, 
for example, the numerical simulation is carried out with the help of Nasya and FLAC3D [6]. The research results show that firstly, the greater the soil cover, the greater the pressure on the tunnel support, the greater the settlement of the soil caused by the new tunnel. This shows that the settlement of the surrounding rock under the subgrade is greater than that under the shoulder. Secondly, because the temporary support can weaken the deformation of soil, the road settlement caused by the Completely Randomized Design (CRD) method with more temporary support is significantly less than that caused by the bench method. According to the research studies $[7,8]$, the deformation control standard, soil improvement technology, and confined water treatment measures of existing stations are to be studied in depth by combining engineering analogy, theoretical research and numerical analysis, combined with geological conditions, and surrounding environment. Reasonable conclusions are obtained by analyzing the impact on existing stations during construction. Similarly, for feasible underground excavation design technical scheme and Movement Joint Spacing (MJS) auxiliary construction, methods of reinforcement, thickness, and relevant parameters are to be considered. By studying the double rectangular concealed excavation construction after MJS reinforcement, the settlement deformation, internal force, and cracks of the existing station structure meet the corresponding protection standards, and the rationality and feasibility of the design scheme are verified. Numerical simulation is one of the methods to examine such issues $[9,10]$. Moreover, numerical simulation is preferred by [5] to ascertain the interaction between the soil and rock, besides the tunnel structure. In order to deeply analyze the safety of the existing tunnel structure under the construction of the new tunnel, this research proposes a numerical simulation model. The model intends to examine the safety of the existing tunnel structure under the construction of new tunnel.

The rest of the article is organized into five sections. Related research work is covered in Section 2. Analysis of tunnel deformation is discussed in Section 3. Section 4 is about the tunnel impact analysis method. Numerical simulation experiments are mentioned in Section 5. Conclusion is written in Section 6.

\section{Literature Review}

Difficulties in the construction of tunnels are always greater than those in other engineering works [10] due to the complex mechanical property of tunnels, stress, and deformation factors. Particularly, the surrounding rocks play a significant role in this regard because the structure is mainly supported by the surrounding rocks in a uniform stress system. To minimize the issues in construction and to ensure future safety, deformation and stability are to be studied prior to the actual construction. Various research works have been carried out in the literature that targets the issues and challenges of tunneling [3]. Franza et al. [11] presented the possible challenges involved in tunnel construction and its effect on the side by buildings. Similarly, the numerical study of Li et al. [12] focused on tunnel construction soft soil. Vulnerability analysis methods based on Building Information Modeling (BIM) Technology have also been studied under the condition of insufficient lining [13]. To analyze the deformation of a tunnel caused by the crossing over of a new tunnel, Liang et al. [14] suggested an analytical method. For the geotechnical engineering analysis, models have been proposed based on numerical methods, such as Discrete Element Method (DEM), Finite Element Method (FEM), and Finite Difference Method (FDM) [15]. The approaches based on DEM [16, 17] are for simulating the deformation of materials due to various quasistatic conditions. The method utilizing FEM in [18] is applicable mainly for analyzing linear solution and phase-field modeling. Abduh proposed the Norwegian method of tunneling [19] for a more than 400-meter long tunneling work. Some state-of-the-art research works from the literature of tunnels simulation are presented in Table 1.

Various software programs have been designed to effectively simulate the geometry of materials and the geological and geotechnical details of various construction materials. Some well-known simulation software programs are FLAC3D, ABAQUS, and CRIPS [5]. The CATIA V5 software of BIM is selected as the core software for simulating the tunnel structure. The specific modeling ideas are given, including tunnel structure model, frame design, parameter setting, information addition, engineering quantity calculation, and model application. The normal section compression bearing capacity of the tunnel structure and the influence of lining thickness are calculated. Following that, the reduction coefficient is introduced to calculate the model stiffness under the influence of lining thickness. The bending deformation method is used to solve the longitudinal deformation curvature radius, crack opening displacement, and maximum deformation value of component connecting bolt stress. The software may also be used for the analysis of tunnel structure vulnerability. The simulation engineering example shows that the soil pressure at the center of the tunnel structure model at the top and bottom in the area with insufficient lining thickness increases and decreases, respectively. The soil pressure at the edge of the area with insufficient lining thickness changes significantly. The vulnerability analysis results of tunnel structure by the proposed method are consistent with the actual measurement results. In [7], the settlement characteristics and control measures of the existing shield tunnel during shield tunneling under the pebble stratum are studied. The research work is about the shield tunneling project of Beijing Metro Line 16 under the existing Metro Line 4. The adaptive transformation of the shield is discussed by analyzing the numerical simulation results of the settlement of the existing tunnel, combining the field monitoring data and shield construction parameters, The law of tunnel settlement is summarized, and the experience of regulating shield construction parameters is expounded.

\section{Analysis of Tunnel Deformation}

3.1. Causes of Tunnel Uplift and Deformation. After completing the existing tunnel, the interaction between the tunnel structure and the surrounding soil attained a stable 
TABLE 1: State-of-the-art systems from the literature of tunneling simulation.

\begin{tabular}{|c|c|c|c|}
\hline Author(s) & Title & Year & Purpose \\
\hline $\begin{array}{l}\text { Abbo et al. } \\
{[20]}\end{array}$ & Undrained stability of wide rectangular tunnels & 2013 & $\begin{array}{l}\text { To investigate the undrained stability of } \\
\text { rectangular tunnels }\end{array}$ \\
\hline $\begin{array}{l}\text { Funatsu et al. } \\
{[21]}\end{array}$ & $\begin{array}{l}\text { Numerical analysis to better understand the mechanism of the } \\
\text { effects of ground supports and reinforcements on the stability of } \\
\text { tunnels using the distinct element method }\end{array}$ & 2008 & $\begin{array}{l}\text { To investigate the dowels and lining issues of } \\
\text { tunnels in sandy land }\end{array}$ \\
\hline $\begin{array}{l}\text { Chen et al. } \\
{[22]}\end{array}$ & $\begin{array}{l}\text { Face stability analysis of shallow shield tu } \\
\text { ground using the discrete elem }\end{array}$ & 2011 & To simulate the causes of tunnel face failure \\
\hline $\begin{array}{l}\text { Xing et al. } \\
{[23]}\end{array}$ & $\begin{array}{c}\text { Investigation of rock mass stability around the tunnels in an } \\
\text { underground mine in USA using three-dimensional numerical } \\
\text { modeling }\end{array}$ & 2017 & $\begin{array}{l}\text { To simulate and investigate the stability of } \\
\text { rock mass around tunnels }\end{array}$ \\
\hline $\begin{array}{l}\text { Jia and Tang } \\
\text { [24] }\end{array}$ & $\begin{array}{c}\text { Numerical study on failure mechanism of the tunnel in a jointed } \\
\text { rock mass }\end{array}$ & 2008 & $\begin{array}{l}\text { To examine layered joints and their effect on } \\
\text { the stability of tunnel using numerical code }\end{array}$ \\
\hline $\begin{array}{l}\text { Wang et al. } \\
{[25]}\end{array}$ & $\begin{array}{c}\text { Numerical simulation of the failure mechanism of circular tunnels in } \\
\text { transversely isotropic rock masses }\end{array}$ & 2012 & $\begin{array}{c}\text { To study the failure mechanism of the circular } \\
\text { tunnel in isotropic rock }\end{array}$ \\
\hline $\begin{array}{l}\text { Liang et al. } \\
{[14]}\end{array}$ & Effects of above-crossing tunneling on the existing shield tunnels & 2016 & $\begin{array}{l}\text { To investigate different factors affecting the } \\
\text { behavior of existing tunnels }\end{array}$ \\
\hline
\end{tabular}

state. The tunnel stress is balanced at a stable state, as shown in Figure 1. It is assumed that the new tunnel is constructed above the tunnel so that the soil under the tunnel has an obvious unloading effect in the vertical direction. Because of this effect, the soil approaches the state of stress release, which leads to uplift deformation. The tunnel above the stress reduced is subjected to additional downward stress, resulting in uplift deformation [26].

In addition, the inner and outer sides of the retaining structure of the foundation pit are subjected to the same size and opposite earth pressure before the construction. At this time, the retaining structure of the resultant force is zero, whereas the displacement is also zero; see Figure 2. After penetration, the inner side of the retaining structure is no longer affected by earth pressure. The earth pressure on the outer side of the structure changes to that in the foundation pit. With the development of the project, the earth pressure in the retaining structure increases with the increase in the elevation difference between the inside and outside of the pit.

\subsection{Reasons for Convergence Deformation of Tunnel Cross} Section. Before the implementation of the project, the coefficient of foundation earth pressure was $K_{0}<1$ and the gravity stress of the soil above the tunnel was higher than the horizontal stress of the two sides. With the advancing of underpass construction, the stress on the top of the tunnel decreases gradually, while the horizontal stress on both sides of the tunnel strengthens continuously. After underpass construction, the gravity stress above the tunnel is lower than the horizontal stress on both sides. Hence, the convergent deformation of the cross section appears. The influence of new tunnel underpass construction on tunnel convergence deformation is shown in Figure 3.

3.3. Finite Element Model Construction. Accurate construction of soil models is the focus of finite element analysis. In the analysis method of Gonzalo et al. [27], the modified tunnel model is used for finite element analysis. The yield surface is shown in Figure 4, and the yield expression is as follows:

$$
\frac{1}{\gamma^{2}}\left(\frac{p}{a}-1\right)^{2}+\left(\frac{t}{M a}\right)-1=0
$$

where $M$ represents the slope of the critical state line on the $p-t$ plane, $a$ represents the value $p$ relative to the ellipse and the critical state line, $\gamma$ belongs to the shape parameter of the regulating yield surface, $\gamma=1$ when $t>M p$, and $\gamma$ is not necessarily 1 when $t<M p$. A schematic diagram of the yield surface of the modified tunnel model is shown in Figure 5.

Generally, $\gamma=1$ in the model adjusts the yield surface according to the value $p_{c}$ of the ellipse yield surface and the $p$-axis intersection. However, when $\gamma$ is less than 1 and $a$ is used as the hardening parameter, the relationship between the two is shown in the following equation:

$$
a=a_{0} \exp \left[\left(1+e_{0}\right) \frac{1-J^{p l}}{\lambda-\kappa J^{p l}}\right],
$$

where $J^{p l}$ represents nominal plastic volume strain $(1+e) /\left(1+e_{0}\right), e_{0}$ represents the original void ratio, $\lambda$ represents the slope of the consolidation curve in the same direction, $\kappa$ represents the bulk modulus, and $a_{0}$ represents the original yield surface area.

Based on the Modified Tunnel Model (MTM), the 3D finite element analysis model is obtained, as shown in Figure 4 . In order to reduce the influence of size effect on the accuracy of numerical simulation, the model size is set to $90 \mathrm{~m} \times 90 \mathrm{~m} \times 90 \mathrm{~m}$, and the model has 52460 units. A three-dimensional incongruent element with eight nodes is used for soil [28], and an integral three-dimensional element with eight nodes is used for pile wall and tunnel structure. The interaction between pile and soil and the interaction between tunnel and soil use contact elements. The normal and tangential behavior of contact surface uses "hard" contact mode and Coulomb's law, respectively. The tangential contact friction coefficient of the existing tunnel and soil is 0.45 . 


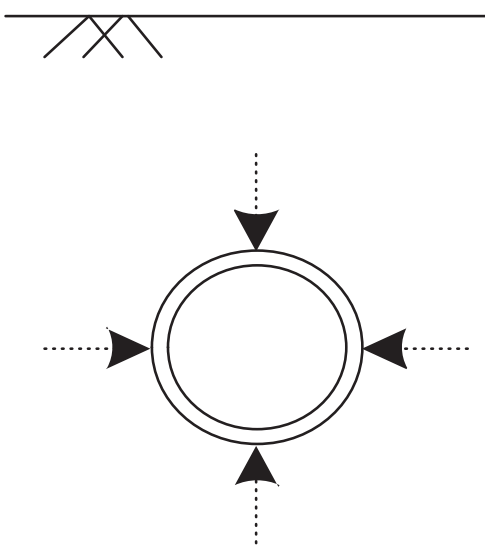

(a)

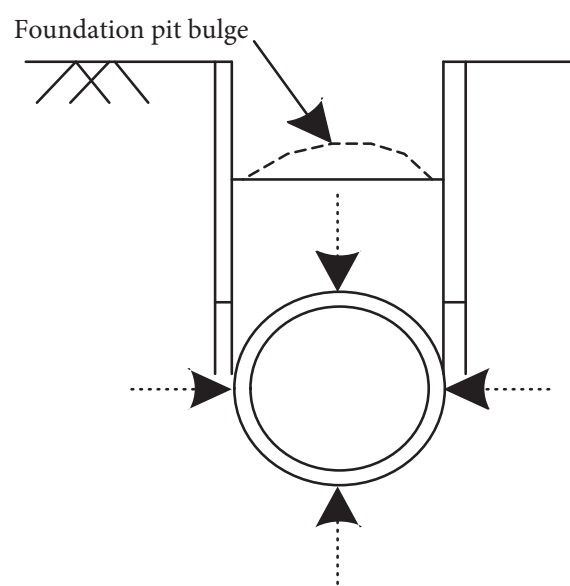

(b)

Figure 1: Schematic diagram of influence of new tunnel underpass construction on tunnel stress state: (a) stress balance state before undercrossing construction; (b) unbalanced stress state after underpass construction.

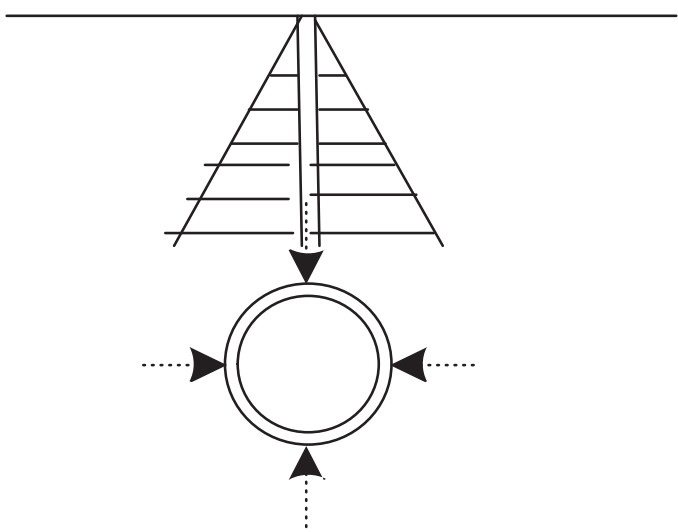

(a)
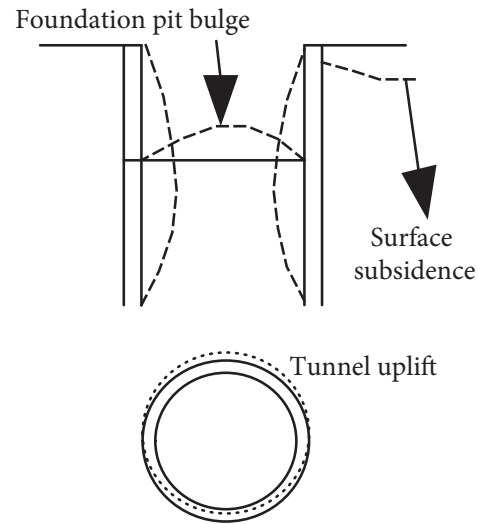

(b)

FIGURE 2: Influence of new tunnel underpass construction on tunnel stress state: (a) stress balance state before undercrossing construction; (b) unbalanced stress state after underpass construction.

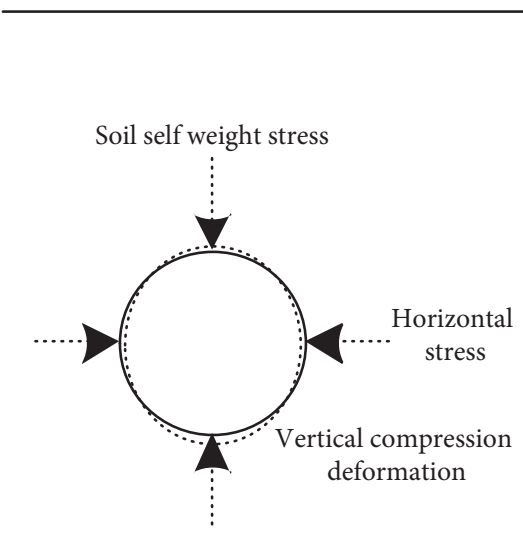

(a)

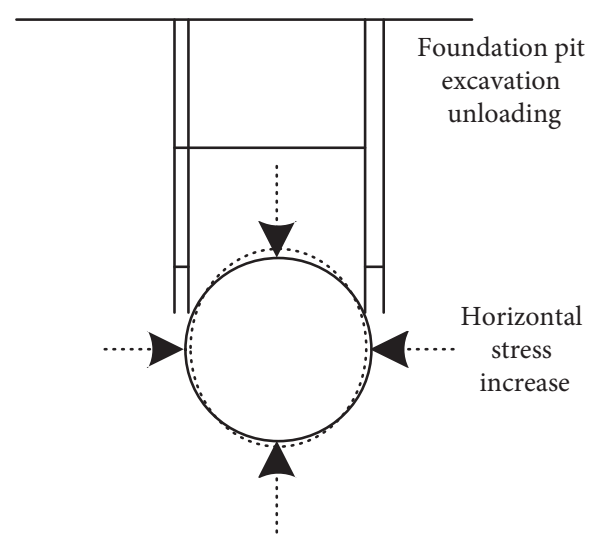

(b)

FIGURE 3: Influence of new tunnel underpass construction on tunnel convergence deformation: (a) stress balance state before undercrossing construction; (b) unbalanced stress state after underpass construction. 


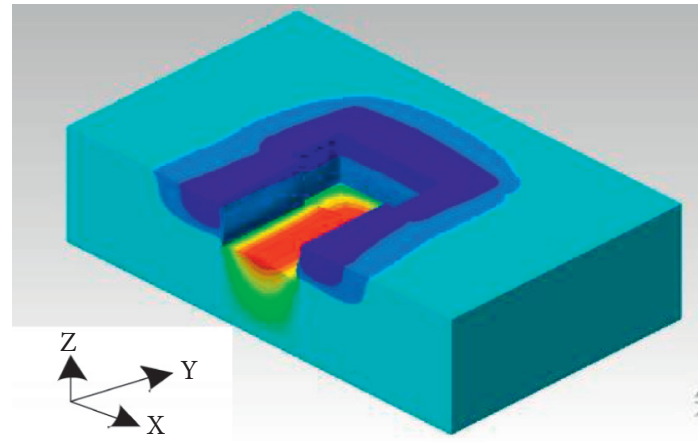

FIGURE 4: Finite element analysis model.

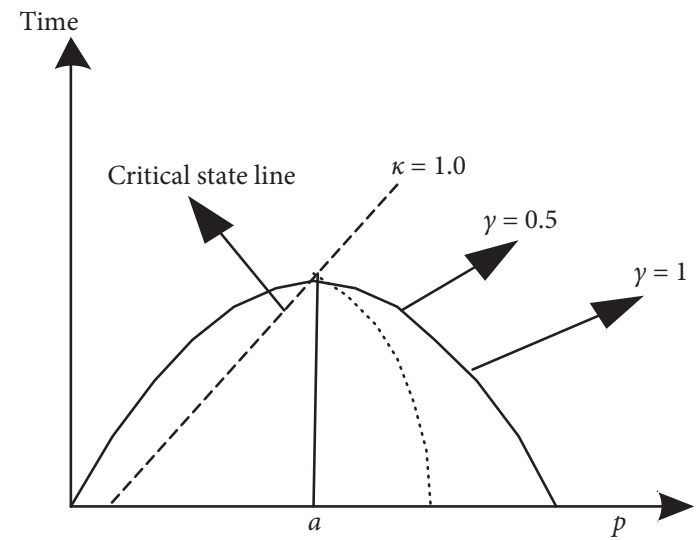

Figure 5: Schematic diagram of yield surface of modified tunnel model.

Figure 6 shows the grid division of the overall pile wall. During the actual underpass construction of the new tunnel, the distance between each pile is $600 \mathrm{~mm}$.

The position relationship between supporting pile and tunnel is shown in Figure 7.

For analysis using the finite element models, the following assumptions need to be made:

(1) Treating soil materials as homogeneous elastoplastic bodies

(2) Treating the retaining pile wall and the existing tunnel as continuous and mean linear elastic body

(3) Disregarding the separation effect of the retaining pile wall and other structures from the soil and regarding the deformation of pile wall, tunnel, and soil as coordinated

(4) Ignoring the time effect in the construction of new tunnels

3.4. Structural Simulation of Tunnels. In order to realize the numerical analysis of the safety of the existing tunnel structure under the construction of the new tunnel, the prestress application control is carried out. The method collectively utilizes the analysis method of the structural safety evaluation parameters of the frame tunnel and the wind load dynamic fitting model. The lateral model is for the

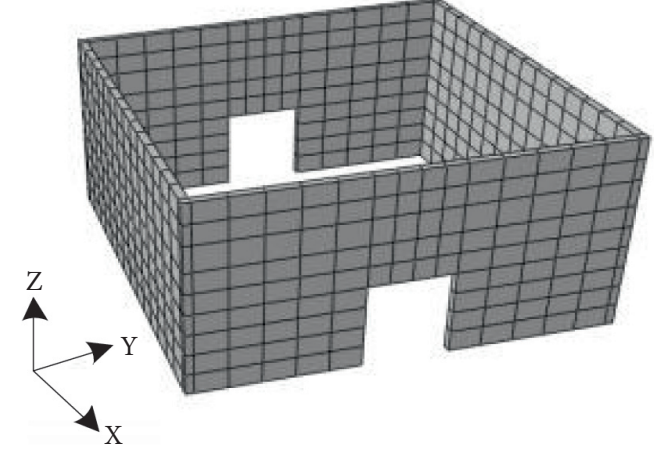

FIGURE 6: Supporting pile wall.

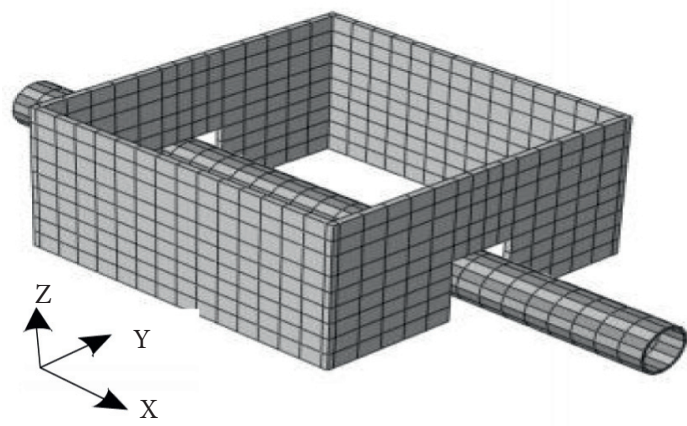

FIGURE 7: Schematic diagram of pile wall and tunnel.

existing tunnel structure under the construction of the new tunnel. According to the uniaxial compression constitutive relationship, the length of the existing tunnel under the construction of the new tunnel is set as $1.5 \mathrm{~km}$. The bearing platform is $12 \mathrm{M} 8 \mathrm{~m}^{3} \mathrm{~m}$, the stress load is $158 \mathrm{kN}$, and the diameter of the tunnel pile is $1 \mathrm{~m}$. The propulsion data acquisition method is adopted, and 34 pile groups are set under the bearing platform for sensor data monitoring [29]. The steel web of the upper lower flange is used as the stiffness collection center of the acting beam. The distance between the centroid axis of the steel beam section of the existing tunnel and the beam bottom height of the new tunnel matters. Therefore, the stress load of the beam section and the safety value of the existing tunnel structure under the construction of the new tunnel are analyzed. The stress parameters, yield response, tensile resistance, and other parameters are taken as the constraint indexes. The tensile reinforcement moment of the existing railway long-span skew frame under the construction of steel beam lower flange and the new tunnel is also analyzed. Under different load conditions, the relationship curve between compressive stress and compressive strain of the existing tunnel structure under the construction of a new tunnel is shown in Figure 8.

Based on the strain curve, as shown in Figure 8, an analytical model of shear capacity in the core area of the column node is obtained [30]. Through the peak stress and the corresponding strain relationship, the safety constraints of the skew frame tunnel are determined. Under the constraint of compression and tension damage index coefficient, 


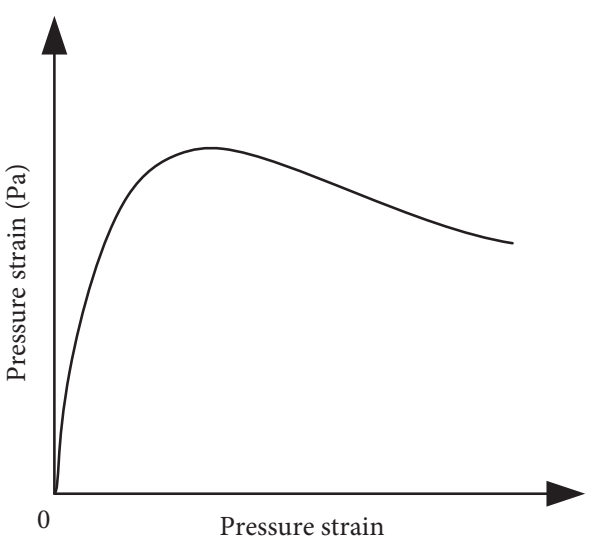

FIgURE 8: Relationship curve between compressive stress and compressive strain of existing tunnel structure during underpass construction of a new tunnel.

the load parameters of railway long-span skew frame tunnel structure are obtained. According to the above analysis, the horizontal load displacement hysteretic analysis model is constructed. Thus, the structural mechanics of the existing tunnel under the construction of the new tunnel is analyzed in combination with the analysis methods of constraint parameters such as axial compression ratio and prestressing force [31].

\section{Design of Tunnel Impact Analysis Method}

4.1. Artificial Bee Colony Algorithm. The artificial bee colony algorithm [32] is used to extract the parameter fusion characteristic quantity of tunnel influence and the buckling support. The equivalent energy consumption state equation is obtained according to the pressure difference of the inner and outer pipe length:

$$
w=\mu_{\mathrm{MCMA}} \cdot d-J_{\mathrm{MCMA}} \cdot b,
$$

where $\mu_{\mathrm{MCMA}}$ represents the buckling support parameter affected by tunnel, $d$ represents the buckling support energy consumption affected by tunnel, $J_{\mathrm{MCMA}}$ represents initial colony position parameter, and $b$ represents initial colony pheromone. Based on the analysis of the influence of the residual deformation on the supporting structure of the tunnel, the characteristic quantities of the supporting inner and outer pipes are obtained, as follows:

$$
x_{i}(n)=\sum_{R=r_{1}}^{r_{n}} \log (R \cdot w)^{2} .
$$

In equation (4), $R=\left\{r_{1}, r_{2}, \ldots, r_{n}\right\}$ represents the distributed node set of the supporting inner and outer pipes affected by the tunnel. Through the homomorphic feature mining method, the dimensionless parameters of the tunnel influence are obtained as follows:

$$
y_{j}(n)=f_{i j}\left\{r_{1}, r_{2}, \ldots, r_{n}\right\} .
$$

In equation (5), $f_{i j}$ represents the evolution speed of the bee colony affected by the tunnel [33]. If the current position of an individual bee colony is $B_{i j}$, let the bee colony analysis weight coefficient $W_{c}<1$ of tunnel impact analysis, get the position parameter distribution of bee colony under the condition of residual deformation as $A[j]$, and let $A[j]=A[j+1]$. Under the condition of no residual deformation of members, the pile bending moment is as follows:

$$
p_{i d}= \begin{cases}B_{i j} \cdot A[j], & \text { if } W_{c}<1, \\ B_{i j} \cdot A[j+1], & \text { if } W_{c} \geq 1 .\end{cases}
$$

According to the above analysis, the characteristic quantity of bending moment calculated by artificial bee colony algorithm with tunnel underpass construction is as follows:

$$
D=\frac{x_{i}(n) \cdot y_{j}(n)}{p_{i d}} .
$$

In the bending moment calculation of pile group under working condition, the tunnel influence displacement value $d_{i j}(t)$ obtained at the $v$ detection point is obtained through iteration $t$; then,

$$
\mathrm{d}_{i j}(t)=\sum_{v=1}^{\infty} \frac{v \cdot x_{i j}(t)}{g_{\text {best }}(t)}
$$

where $x_{i j}(t)$ represents the time series of tunnel affecting displacement detection and $g_{\text {best }}(t)$ represents the fitness function.

4.2. Tunnel Impact Analysis Output. Under the condition of additional mode, a model for estimating the moment of pile group affected by tunnel is established [34], and the optimal analytical set of parameters for impact analysis is $P_{g}=\left\{p_{g 1}, p_{g 2}, \ldots, p_{g D}\right\}$. The axial force of pile group affected by the tunnel at moment $(t+1)$ is obtained by bee colony evolution:

$$
E(t+1)=c_{i}+r_{i} \cdot\left\{p_{g 1}, p_{g 2}, \ldots, p_{g D}\right\} .
$$

In equation (9), $c_{i}$ represents the coefficient of pile foundation under the tunnel and $r_{i}$ represents the velocity affected by the tunnel.

Under the assumption that $a$ is the tunnel influence coefficient and the influence of the matrix soil layer on the analysis results is ignored, the tunnel influence analysis results are obtained:

$$
Q=\frac{\left[d_{\text {mean }}(t)-d_{\text {max }}(t)\right] \cdot a \cdot d_{i j}}{d_{\text {max }}(t) \cdot O},
$$

where $d_{\text {mean }}(t)$ is the average value of horizontal displacement to the tunnel, $d_{\max }(t)$ is the most influential displacement, and $O$ is the dynamic change parameter of the supporting structure.

Through the above process, the method of tunnel influence analysis based on artificial bee colony algorithm is designed.

4.3. Analysis Model of Horizontal Load Parameters of Joint Specimens. According to the tensile stress-strain relationship of the horizontal load of the joint specimen, the 

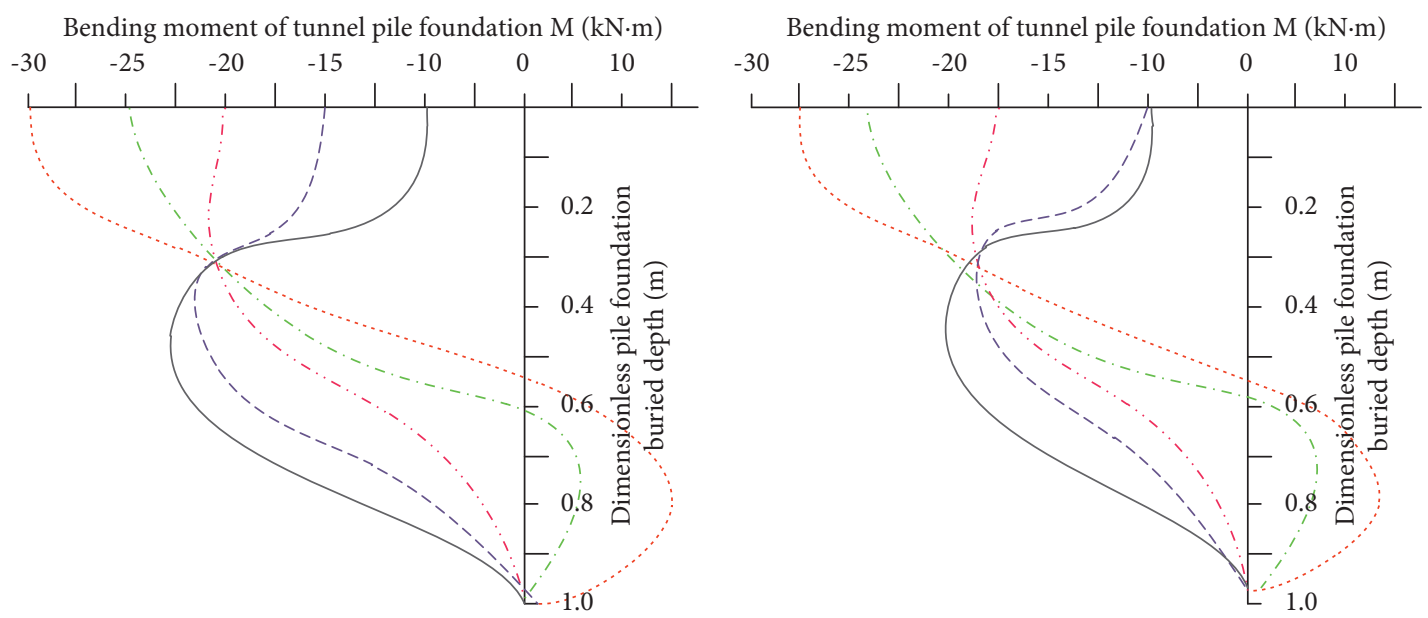

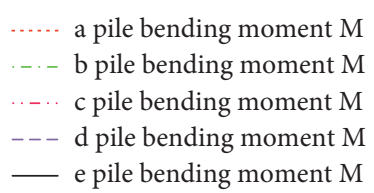

(a)

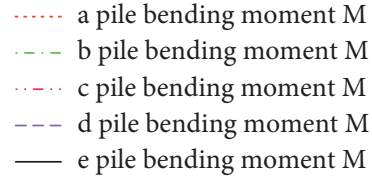

(b)

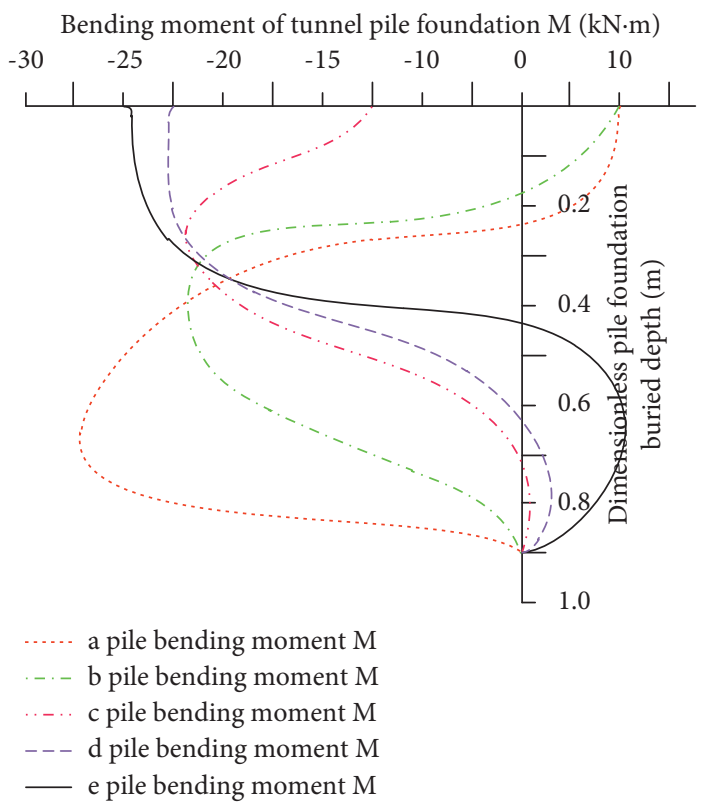

(c)

Figure 9: Bending moment test results of node specimen under horizontal load. (a) Pile foundation of tunnel 1; (b) pile foundation of tunnel 2; (c) pile foundation of tunnel 3 .

horizontal shear strength analysis model of the existing tunnel structure under the construction of the new tunnel is computed [35]. Taking the steel such as I-beam, longitudinal reinforcement, and stirrup as the specimen, the mean value of the residual stress is obtained as the elastic deformation increment of the existing tunnel structure under the construction of the new tunnel. The stiffness of the steel-reinforced section of the existing tunnel structure under the construction of the new tunnel is set as $55 \mathrm{kN} \cdot \mathrm{m}$. The horizontal displacement SX is $12 \mathrm{M}$, and the maximum value of axial force loading is $1400 \mathrm{kN} \sim 1600 \mathrm{kN}$. Taking the pile foundations of No. 1, No. 2, and No. 3 parallel tunnels as the test objects, the bending moment test results of the horizontal load of the joint specimens are obtained through the fusion of the horizontal load parameters of the joint specimens, as shown in Figure 9.

According to the test results, shown in Figure 10, the stiffness of the steel strengthening section is subjected to stress loading under different loads [36]. The axial force increases by $3 \% \sim 4 \%$ along the pile body. At the same time, the stress-strain relationship under reciprocating load is obtained, as shown in Figure 10. 


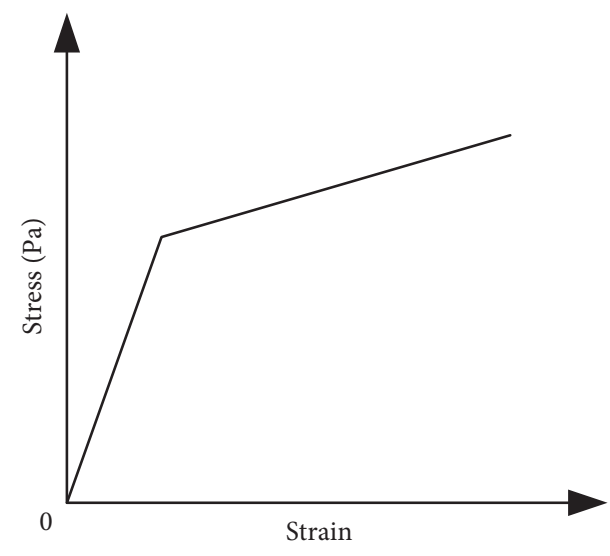

FIGURE 10: Stress-strain relationship under reciprocating load.

On this basis, the threefold line model is adopted to analyze the structural mechanics of the existing tunnel under the construction of the new tunnel [37] so as to improve the bearing capacity of the existing tunnel under the construction of the new tunnel.

\section{Numerical Simulation Experiment}

5.1. Axial Distance Effect on Stress and Deformation. In order to realize the numerical simulation of the distance between the longitudinal axis of the tunnel and the axis of the foundation pit on the stress and deformation of the tunnel, the values of $x_{0}$ are $0 \mathrm{~m}, 20 \mathrm{~m}$, and $40 \mathrm{~m}$ are used, respectively [38]. The distance between the longitudinal axis and the foundation pit axis changes accordingly. The trend of additional vertical stress $\sigma_{z}(y)$ on the tunnel axis is shown in Figure 11.

Through the analysis of Figure 11, it can be concluded that the additional stress caused by the construction of new tunnels decreases rapidly with the increase of the longitudinal axis. As the distance between the longitudinal axis and the excavation axis increases, the additional stress decreases. Moreover, the maximum vertical displacement and the maximum bending moment decrease simultaneously. From the above analysis, we can see that the distance from the axis of the foundation pit has a more obvious impact on the stress and deformation of the tunnel. Hence, it is deduced that the actual construction process should be far from the tunnel.

5.2. Influence of Underpass Construction Depth on Tunnel. In order to realize the numerical simulation of the stress and deformation of the existing tunnel at the construction depth $d_{1}$ of the new tunnel, the values of $d_{1}$ are kept as $15 \mathrm{~m}, 10 \mathrm{~m}$, and $5 \mathrm{~m}$, respectively. When the underpass construction depth changes continuously, the change of additional vertical stress $\sigma_{z}(y)$ generated on the tunnel axis is shown in Figure 12.

From Figure 12, it is clear that when the construction depth of the underpass is $3 \mathrm{~m}$, the additional stress is small. Similarly, when it gets deepened, the additional stress

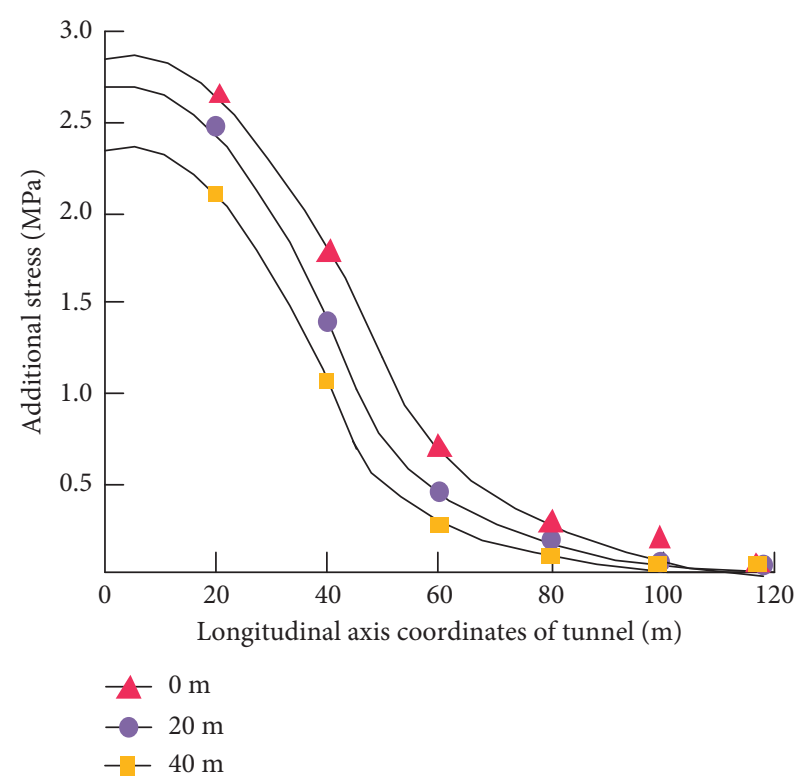

FIgURE 11: Stress distribution along tunnel axis.

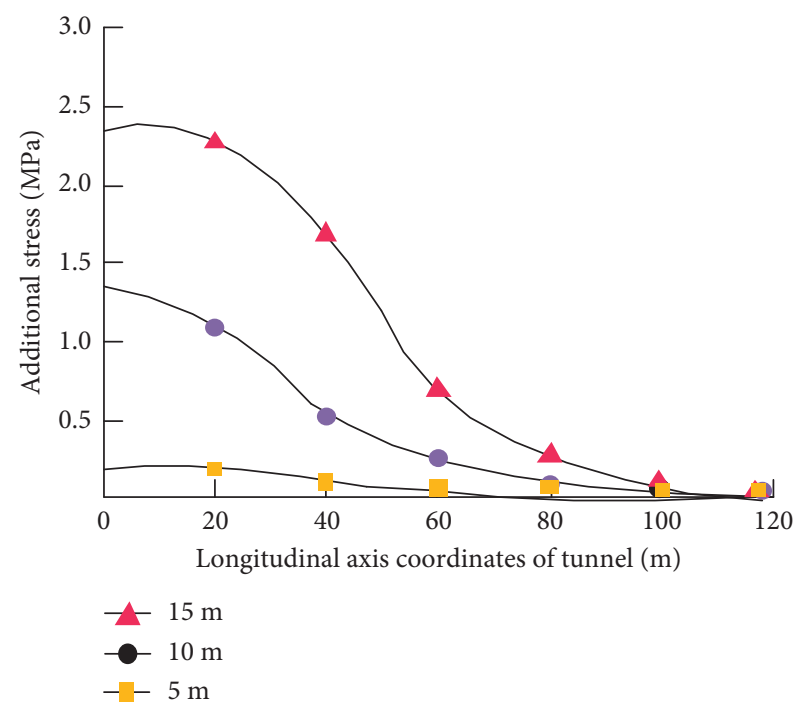

FIgURE 12: Variation diagram of the additional stress of lower axis at different undercrossing construction depths.

increases. It shows that the construction depth of the new tunnel also has a great impact on the tunnel.

\subsection{Influence of Different Underpass Construction Methods on} Tunnel. In addition to the above two factors on the deformation of the impact of the tunnel, this article also carried out a different method of construction of the tunnel drawing deformation based on numerical simulation.

Figure 13 shows the influence of different penetration methods on the uplift of existing tunnels. As shown in Figure 13, the uplift value of the construction method of digging through strips at intervals is slightly lower than that of digging through strips at intervals. Therefore, it is 


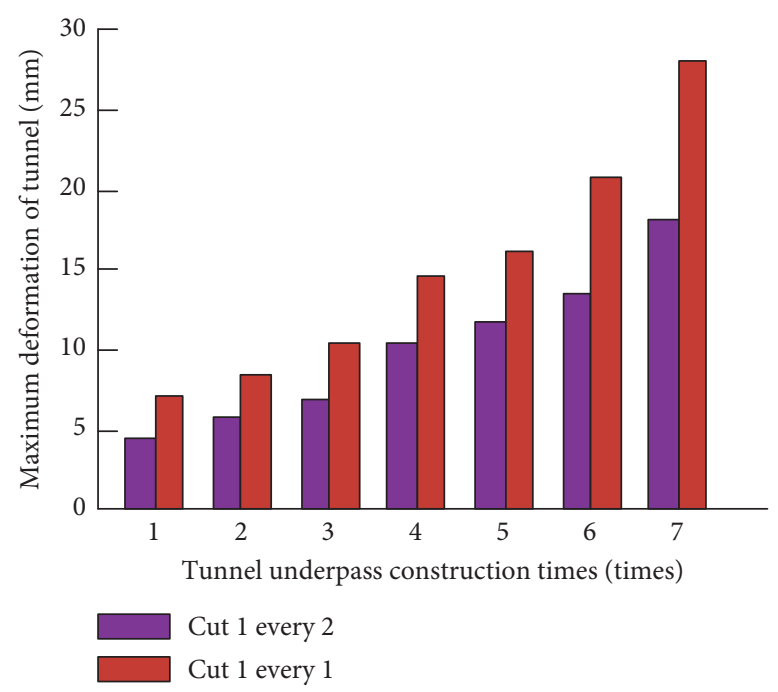

FiguRE 13: Maximum deformation of the tunnel under different underpass construction methods.

TABle 2: Structural parameters of existing tunnel specimens for new tunnel underpass construction.

\begin{tabular}{lccc}
\hline Specimen number & Shear bearing capacity $(\mathrm{kN})$ & Load than $\left(\mathrm{L}^{+} \mathrm{D}^{-1}\right)$ & The yield rate $\left(\mathrm{mm}+\mathrm{s}{ }^{-1}\right)$ \\
\hline 1 & $547 * 644$ & 35 & 2.15 (quasistatic) \\
2 & $457 * 644$ & 65 & 1.45 \\
5 & $574 * 467$ & 65 & 1.22 \\
4 & $624 * 467$ & 62 & 1.65 \\
5 & $475 * 455$ & 85 & 1.66 \\
6 & $540 * 454$ & 25 & 1.67 \\
7 & $470 * 6920$ & 36 & 1.55 \\
\hline
\end{tabular}

suggested to choose the way of drawing out after two excavations in the new tunnel.

\subsection{Safety Test of Existing Tunnel Structure in Underpass} Construction of New Tunnel. The existing tunnel under the construction of the new tunnel is divided into 24 groups of single connecting members and 46 groups of multi-connecting members with a peak load of $2800 \mathrm{kN}$. The structural parameters of the test pieces of the existing tunnel under the construction of the new tunnel are shown in Table 2.

According to the component parameters set above, the distribution of structural safety parameters of existing tunnels under the construction of new tunnels is shown in Figure 14.

It can be seen from the analysis of Figure 15 that the method in this article can effectively realize the numerical analysis of structural safety of the existing tunnel under the construction of the new tunnel. In the negative moment area of the composite beam, the test results of the tangent elastic modulus of the existing tunnel under the construction of the new tunnel are shown in Figure 15.

By increasing the tangent modulus, the increase of the axial force along the pile body is controlled at 3\% 4\%. The influence on the settlement of the pile is observed as uniform.

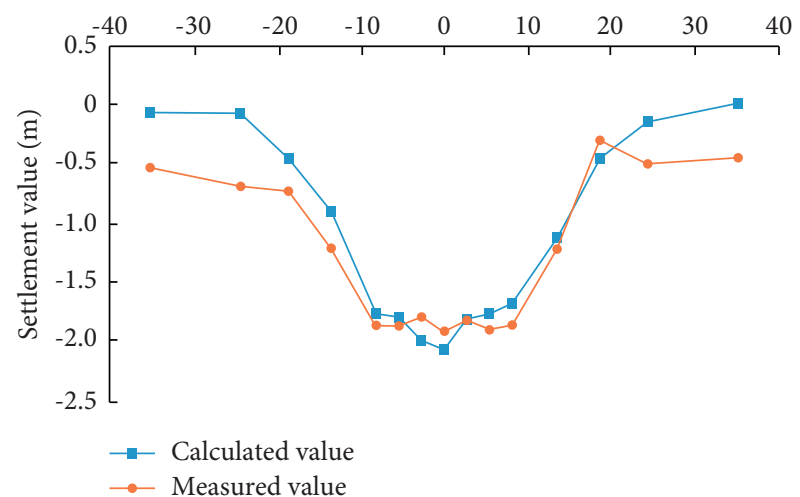

FIgURE 14: Analysis of safety parameters of the existing tunnel under construction of the new tunnel.

The horizontal loads and shear forces of the safety constraint parameters are tested and the results are shown in Figure 16.

It can be seen from the analysis of Figure 16 that the numerical analysis of the safety of the existing tunnel under the construction of the new tunnel is carried out by this method, and the estimation accuracy of the horizontal load and shear parameters is high. Therefore, the maximum displacement of the long-span skew frame tunnel is reduced by about $60 \%$, and the change of the axial force is controlled within $0.5 \%$. 


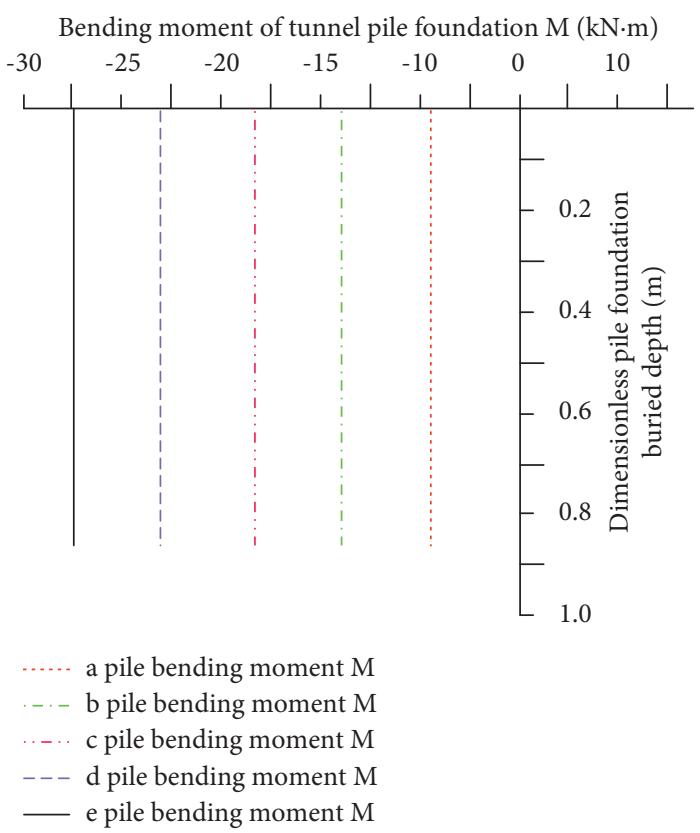

FiguRE 15: Test results of tangent elastic modulus.

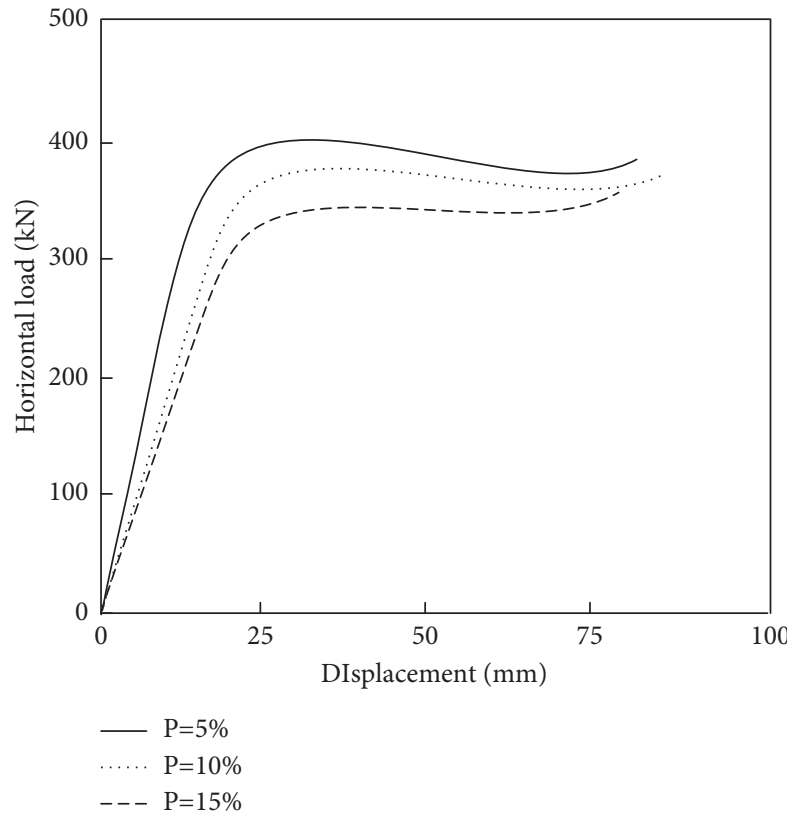

(a)

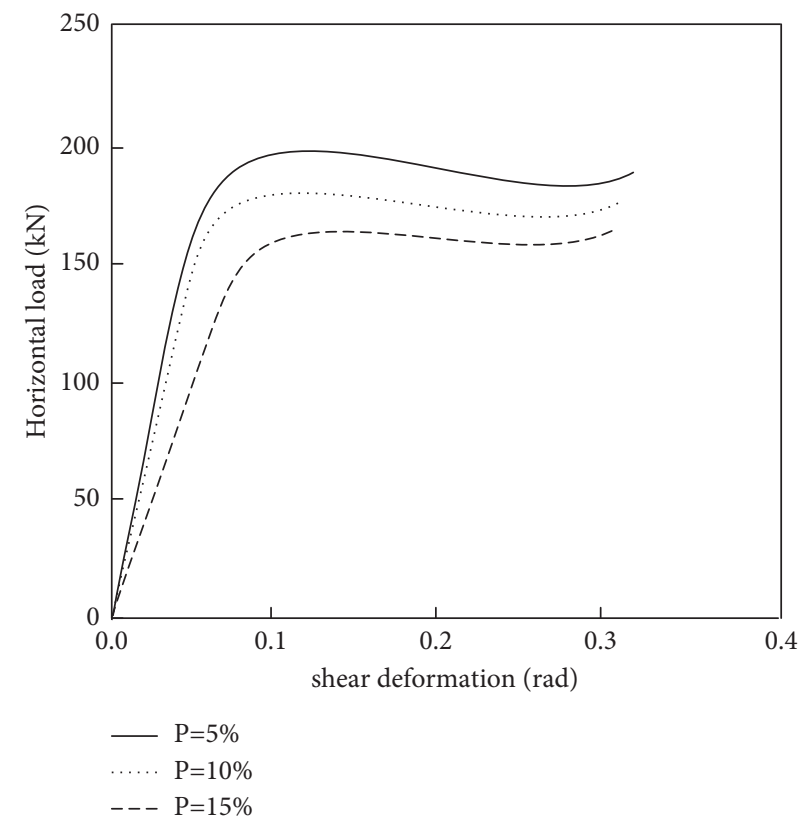

(b)

FIGURE 16: Numerical analysis results of horizontal load and shear force of safety restraint parameters. (a) Horizontal load; (b) shearing force.

\section{Conclusion}

Tunnels have been constructed to overcome congestion and topographical barriers. In order to study the settlement characteristics and control measures of existing tunnels under new tunnels, a numerical simulation model for the safety of existing tunnels under new tunnels is proposed. In order to optimize the simulation accuracy of tunnel structural safety, the reasons for pile foundation uplift are analyzed, and the existing tunnel structural conditions are simulated. In order to improve the accuracy of structural safety estimation of existing tunnels under new tunnels, the parameter fusion eigenvalue of tunnel influence is extracted and the estimation model of pile group moment is constructed. Through the analysis of the existing tunnel structure mechanics, the numerical fitting ability is ideal, which provides a reliable basis for the related domain thorough research. 


\section{Data Availability}

The data used to support the findings of this study are available from the corresponding author upon request.

\section{Conflicts of Interest}

The author declares that he has no conflicts of interest.

\section{Acknowledgments}

This work was supported by the Public Technology Application Research Project of Zhejiang Province in 2019, "Research on Mechanical Influence and Safety Control of Newly-built Metro Shielding Tunnel Passing through Existing Tunnel" (LGF19E080002).

\section{References}

[1] M. Jafari, "System identification of a soil tunnel based on a hybrid artificial neural network-numerical model approach," Iranian Journal of Science and Technology - Transactions of Civil Engineering, vol. 44, no. 1, pp. 560-572, 2020.

[2] P. Bernardi, E. Michelini, A. Sirico, S. Rainieri, and C. Corradi, "Simulation methodology for the assessment of the structural safety of concrete tunnel linings based on CFD fire - FE thermo-mechanical analysis: a case study," Engineering Structures, vol. 225, Article ID 111193, 2020.

[3] H. Khabbaz, R. Gibson, and B. Fatahi, "Effect of constructing twin tunnels under a building supported by pile foundations in the Sydney central business district," Underground Space, vol. 4, no. 4, pp. 261-276, 2019.

[4] M. Cai, "Influence of stress path on tunnel excavation response - numerical tool selection and modeling strategy," Tunnelling and Underground Space Technology, vol. 23, no. 6, pp. 618-628, 2008.

[5] V. Ghiasi, "Risk management overview of tunnels using numerical modeling," Journal of Engineering, Design and Technology, vol. 9, no. 1, pp. 110-124, 2011.

[6] M. M. Ma and Y. S. Ji, "Influences of new tunnel underpass construction on existing expressway and study on construction method optimization," Highway Engineer, vol. 45, no. 1, pp. 140-145, 2020.

[7] W. H. Ma, C. Y. Yang, and H. Peng, "On settlement control of shield tunnels underneath traversing existing dual shield tunnels in gravel layer," Journal of Taiyuan University of Technology, vol. 51, no. 3, pp. 372-379, 2020.

[8] L. Y. Zhao and Y. T. Zhang, "Deformation control and influence analysis of underground tunnel passing through existing subway station," Journal of Xi'an University of Science and Technology, vol. 40, no. 5, pp. 878-886, 2020.

[9] F. Gao and X. Tan, "Stability analysis on large section tunnel with double-side-drift method," Journal of Chongqing Jianzhu University: Natural Science, vol. 3, p. 363, 2010.

[10] B. Zhu, K. Weifeng, X. Jiami, and S. Yanjun, "Numerical simulation research of construction method for shallow buried large section tunnel," The Open Civil Engineering Journal, vol. 10, no. 1, 2016.

[11] A. Franza, A. M. Marshall, T. Haji, A. O. Abdelatif, S. Carbonari, and M. Morici, "A simplified elastic analysis of tunnel-piled structure interaction," Tunnelling and Underground Space Technology, vol. 61, pp. 104-121, 2017.
[12] S.-c. Li, H.-l. Liu, L.-p. Li, Q.-q. Zhang, K. Wang, and K. Wang, "Large scale three-dimensional seepage analysis model test and numerical simulation research on undersea tunnel," Applied Ocean Research, vol. 59, pp. 510-520, 2016.

[13] H. C. Shi, "Simulation study on vulnerability of tunnel structure under insufficient lining thickness," Computer Simulation, vol. 36, no. 7, pp. 230-233, 2019.

[14] R. Liang, T. Xia, Y. Hong, and F. Yu, "Effects of above-crossing tunnelling on the existing shield tunnels," Tunnelling and Underground Space Technology, vol. 58, pp. 159-176, 2016.

[15] Z. Huang, Z. Chenlong, F. Helin, D. Huangshi, M. Shaokun, and F. Jiajun, "Numerical study on the disturbance effect of short-distance parallel shield tunnelling undercrossing existing tunnels," Advances in Civil Engineering, vol. 2020, Article ID 8810658, 14 pages, 2020.

[16] E. V. Shilko, S. G. Psakhie, S. Schmauder, V. L. Popov, S. V. Astafurov, and A. Y. Smolin, "Overcoming the limitations of distinct element method for multiscale modeling of materials with multimodal internal structure," Computational Materials Science, vol. 102, pp. 267-285, 2015.

[17] L. Sun, C. Zhou, D. Qin, and L. Fan, "Application of extended distinct element method with lattice model to collapse analysis of RC bridges," Earthquake Engineering \& Structural Dynamics, vol. 32, no. 8, pp. 1217-1236, 2003.

[18] X. Zhuang, S. Zhou, M. Sheng, and G. Li, "On the hydraulic fracturing in naturally-layered porous media using the phase field method," Engineering Geology, vol. 266, Article ID 105306, 2020.

[19] M. Abduh, "Simulation of tunneling construction methods of the Cisumdawu toll road," AIP Conference Proceedings, vol. 1903, no. 1, 2017.

[20] A. Abbo, D. Wilson, S. Sloan, and A. Lyamin, "Undrained stability of wide rectangular tunnels," Computers and Geotechnics, vol. 53, pp. 46-59, 2013.

[21] T. Funatsu, T. Hoshino, H. Sawae, and N. Shimizu, "Numerical analysis to better understand the mechanism of the effects of ground supports and reinforcements on the stability of tunnels using the distinct element method," Tunnelling and Underground Space Technology, vol. 23, no. 5, pp. 561-573, 2008.

[22] R. P. Chen, L. J. Tang, D. S. Ling, and Y. M. Chen, "Face stability analysis of shallow shield tunnels in dry sandy ground using the discrete element method," Computers and Geotechnics, vol. 38, no. 2, pp. 187-195, 2011.

[23] Y. Xing, P. H. S. W. Kulatilake, and L. A. Sandbak, "Investigation of rock mass stability around the tunnels in an underground mine in USA using three-dimensional numerical modeling," Rock Mechanics and Rock Engineering, vol. 51, no. 2, pp. 579-597, 2018.

[24] P. Jia and C. A. Tang, "Numerical study on failure mechanism of tunnel in jointed rock mass," Tunnelling and Underground Space Technology, vol. 23, no. 5, pp. 500-507, 2008.

[25] S. Y. Wang, S. W. Sloan, C. A. Tang, and W. C. Zhu, "Numerical simulation of the failure mechanism of circular tunnels in transversely isotropic rock masses," Tunnelling and Underground Space Technology, vol. 32, pp. 231-244, 2012.

[26] M. S. P. Wan, J. R. Standing, D. M. Potts, and J. B. Burland, "Pore water pressure and total horizontal stress response to EPBM tunnelling in London clay," Géotechnique, vol. 69, no. 5, pp. 434-457, 2019.

[27] R. S. Gonzalo, G. F. Angel, L. Alberto, R. Raveendra, and T. P Orodea, "Toronto-york spadina subway extension tunnelling under schulich building," Canadian Journal of Civil Engineering, vol. 46, 2019. 
[28] T. Tichý, J. Brož, Z. Bělinová, and R. Pirník, "Analysis of predictive maintenance for tunnel systems," Sustainability, vol. 13, no. 7, p. 3977, 2021.

[29] K. Bergmeister, P. Brunello, M. Pachera, F. Pesavento, and B. A. Schrefler, "Simulation of fire and structural response in the Brenner Base Tunnel by means of a combined approach: a case study," Engineering Structures, vol. 211, Article ID 110319, 2020.

[30] M. S. Alam, N. Sultana, and S. M. Z. Hossain, "Bayesian optimization algorithm based support vector regression analysis for estimation of shear capacity of FRP reinforced concrete members," Applied Soft Computing, vol. 105, Article ID 107281, 2021.

[31] M. T. Kazemi, M. Sharifi, and J. Yang, "Mechanism analysis of steel frames considering moment-shear interaction," $A d$ vances in Structural Engineering, vol. 22, no. 1, pp. 254-267, 2019.

[32] D. Bajer and B. Zorić, "An effective refined artificial bee colony algorithm for numerical optimisation," Information Sciences, vol. 504, pp. 221-275, 2019.

[33] J. Meshkati and F. Safi-Esfahani, "Energy-aware resource utilization based on particle swarm optimization and artificial bee colony algorithms in cloud computing," The Journal of Supercomputing, vol. 75, no. 5, pp. 2455-2496, 2019.

[34] C. Medina, G. M. Álamo, L. A. Padrón, J. J. Aznárez, and O. Maeso, "Application of regression models for the estimation of the flexible-base period of pile-supported structures in continuously inhomogeneous soils," Engineering Structures, vol. 190, pp. 76-89, 2019.

[35] A. P. Singh and K. Chatterjee, "Influence of soil type on static response of cantilever sheet pile walls under surcharge loading: a numerical study," Arabian Journal of Geosciences, vol. 13, no. 3, p. 138, 2020.

[36] F. Dumbrava and C. Cerbu, "Experimental study on the stiffness of steel beam-to-upright connections for storage racking systems," Materials, vol. 13, no. 13, p. 2949, 2020.

[37] W. Zhong, Q. Huang, F. Zheng et al., "Structural insight into the abnormal capacity of a Co-substituted tunnel-type $\mathrm{Na} 0.44 \mathrm{MnO}_{2}$ cathode for sodium-ion batteries," ACS Applied Materials \& Interfaces, vol. 12, no. 42, pp. 47548-47555, 2020.

[38] M. Li, H. Jiang, Y. Hao et al., "A systematic review on botany, processing, application, phytochemistry and pharmacological action of Radix Rehmnniae," Journal of Ethnopharmacology, vol. 114820, 2021, In press. 